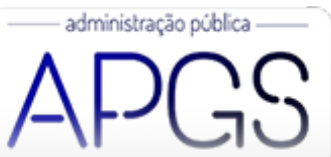

Administração Pública e Gestão Social ISSN: 2175-5787

apgs@ufv.br

Universidade Federal de Viçosa

Brasil

\title{
Perspectivas do Território no Sistema Agroalimentar Localizado: o Caso da Uva no Município de Marialva-PR
}

Pereira, Jaiane Aparecida; Borgonhoni Chagas, Priscilla; Schiavi Bánkuti, Sandra Mara

Perspectivas do Território no Sistema Agroalimentar Localizado: o Caso da Uva no Município de Marialva-PR

Administração Pública e Gestão Social, vol. 11, núm. 2, 2019

Universidade Federal de Viçosa, Brasil

Disponível em: http://www.redalyc.org/articulo.oa?id=351558326001

Esta obra está bajo una Licencia Creative Commons Atribución-NoComercial-SinDerivar 3.0 Internacional. 
Perspectivas do Território no Sistema Agroalimentar Localizado: o Caso da Uva no Município de Marialva-PR

\author{
Territory perspectives in a Localized Agri-food System: the case of grape in Marialva-PR \\ Perspectivas del Territorio en el Sistema Agroalimentario Localizado: el Caso de la Uva en el Municipio de \\ Marialva-PR
}

Jaiane Aparecida Pereira

Universidade Estadual de Maringá, Brasil

jaiane.pereira@ufms.br

Redalyc: http://www.redalyc.org/articulo.oa?

Priscilla Borgonhoni Chagas

Universidade Federal do Rio Grande do Sul, Brasil

pbchagas@uem.br

Sandra Mara Schiavi Bánkuti

Universidade Federal de São Carlos, Brasil

smsbankuti@uem.br

$\mathrm{id}=351558326001$

Recepção: 24 Agosto 2016
Aprovação: 18 Dezembro 2017
Publicado: 01 Abril 2019

\title{
Resumen:
}

El presente trabajo tiene por objetivo comprender las acciones y los actores que configuran a Marialva, en el estado de Paraná, Brasil, como un territorio productor de uvas finas. Se articulan teóricamente cuestiones sobre territorio y desarrollo territorial y sobre Sistema Agroalimentario Localizado (SIAL), que es un tipo de arreglo que involucra relaciones de producción organizadas horizontal y verticalmente que emergen a partir de la acción colectiva y de la coordinación local en torno a un recurso territorializado. Para esto, se realizó una investigación descriptiva, con datos secundarios y análisis documental. Se admiten avances analíticos al combinar la perspectiva del SIAL con un enfoque ampliado de territorio, teniendo en cuenta que un sistema agroalimentario localizado involucra no sólo aspectos económicos y sociales, sino también aspectos políticos, culturales y de la naturaleza, recíprocamente relacionados. Se subraya la necesidad de que el desarrollo local sea objeto de discusión y análisis por parte de los agentes públicos y de la sociedad civil organizada con vistas a un mayor desarrollo territorial.

Palabras Clave: Terrritorio, Desarrollo territorial, Sial.

\section{Resumo:}

O presente trabalho tem por objetivo compreender as ações e os atores que configuram o município de Marialva (PR) como um território produtor de uva fina. Articulam-se teoricamente questões sobre território e desenvolvimento territorial e sobre Sistema Agroalimentar Localizado (SIAL), que é um tipo de arranjo envolvendo relações de produção organizadas horizontal e verticalmente que emergem a partir da ação coletiva e da coordenação local em torno de um recurso territorializado. Para tanto, foi realizada uma pesquisa descritiva, com dados secundários e análise documental. Admitem-se avanços analíticos ao combinar a perspectiva do SIAL com uma abordagem ampliada de território, haja vista que um sistema agroalimentar localizado envolve não só aspectos econômicos e sociais, mas também aspectos políticos, culturais e da natureza, reciprocamente relacionados. Frisase a necessidade de que o desenvolvimento local seja alvo de discussão e análise por parte dos agentes públicos e da sociedade civil organizada, tendo em vista um maior desenvolvimento territorial.

PalaVRas-CHAVE: Território, Desenvolvimento territorial, SIAL.

\section{Abstract:}

This paper intents to understand actors and actions comprising Marialva, in the state of Paraná, Brazil, as a fine grape production territory. The theoretical issues involve concerns about territory and territorial development, as well as Localized Agri-Food System (LAFS), a type of arrangement that comprises horizontal and vertical relations, collective actions and coordination of production within a territorialized resource. This qualitative descriptive research included secondary data and document analysis. We noticed 
an analytical improvement when combining LAFS perspective and a wider territorial approach, once a local agri-food system comprises not only economic and social aspects, but political, cultural and natural features as well. In this sense, public agents and the civil society need to promote discussions on local development, directed to improvements in territorial development.

KEYWORDS: Territory, Territorial Development, LAFS.

\section{INTRODUÇÃo}

O setor agropecuário no Brasil configura um modo usual de acessar os mercados nacional e internacional. Sua importância é fundamental para o desenvolvimento econômico e social do país, correspondendo a $23 \%$ do Produto Interno Bruto (PIB) e a $48 \%$ das exportações totais (Confederação da Agricultura e Pecuária do Brasil, 2016). O setor também é de grande importância para o Paraná, uma vez que responde por mais de $30 \%$ do PIB do estado, sendo o segundo maior polo da produção agroindustrial brasileira e destaque nas vendas externas (Instituto Paranaense de Desenvolvimento Econômico e Social [IPARDES], 2017). Contudo, o desenvolvimento nos moldes capitalistas com grandes mercados globais de commodities não é o único modelo de negociação existente. Atualmente, passa a ser considerado o espaço local, no qual as potencialidades e recursos são aproveitados dentro de uma estratégia dos atores sociais, que inclui a organização do território e políticas de desenvolvimento local (Moraes \& Schneider, 2010).

Os fatores territoriais e culturais se tornam relevantes para configuração da economia de uma região. Portanto, outras formas produtivas locais, representadas por produtos típicos ou tradicionais começam a atender às novas demandas dos consumidores, agregando diferenciais qualitativos aos alimentos, como cuidados ambientais, tradições, cultura local e a paisagem rural (Specht \& Ruckert, 2008).

Dentro deste contexto, surge a abordagem do Sistema Agroalimentar Localizado (SIAL), que é definido como um sistema que integra diversas organizações de produção e de serviço, que estão vinculadas por suas características a um território específico. No sistema envolvem-se produtos, pessoas, instituições, entre outros. Todos esses componentes se combinam em uma organização agroalimentar bem definida e reconhecida (Boucher \& González, 2011). Na abordagem do SIAL, as relações de produção arranjadas horizontal e verticalmente emergem a partir da ação coletiva e da coordenação local em torno de um recurso territorializado (Ambrosini, Filippi, \& Miguel, 2009).

Vários estudos apontam a formação de diferentes arranjos que tem características de SIAL no Brasil. O caso do queijo Serrano produzido na microrregião dos Campos de Cima da Serra no Rio Grande do Sul e na Serra do Rio do Rastro em Santa Catarina e os queijos artesanais, produzidos em Minas Gerais e no Nordeste (Ambrosini et al., 2009; Krone, Thomé da Cruz, \& Menasche, 2010; Menezes, 2011); os morangos do Vale do Caí no Rio Grande do Sul (Specht \& Ruckert, 2008; Specht, 2014); a carne dos Pampas Gaúchos no Rio Grande do Sul (Malafaia \& Barcellos, 2006; Malafaia, Barcellos, Aguiar, Azevedo, \& Pinto, 2007); a maricultura em Santa Catarina (Lins, 2006); a exploração do pequi na região norte de Minas Gerais (Cândido, Malafaia, \& Rezende, 2012) e o café especial do norte pioneiro do Paraná (Lourenzani, Bankuti, $\&$ Peterson, 2013).

Em todos os casos, nota-se que os aspectos territoriais são muito importantes para a formação do SIAL, sendo esse um espaço elaborado, fruto de uma construção social, impregnada de características culturais (Diáz-Bautista, 2001). Entretanto, a literatura acerca do tema lança mão do conceito de território de uma forma superficial, sem uma discussão aprofundada sobre qual a perspectiva adotada. Aliado a isso, Muls (2008) reitera que as teorias tradicionais do desenvolvimento são insuficientes para o adequado tratamento das experiências de desenvolvimento localizado, abrindo espaço para outras perspectivas, como a territorial.

A partir dessa discussão, o avanço teórico aqui proposto fundamenta-se no pressuposto de que o conceito de território é amplo e engloba variáveis políticas, econômicas, culturais e naturais reciprocamente relacionadas (Haesbaert, 2004; Saquet, 2009). O território, então, é considerado um produto histórico, com mudanças que ocorrem em um ambiente no qual se desenvolve uma sociedade. Para Saquet (2009, p. 
81), "o território é considerado produto de mudanças e permanências ocorridas num ambiente no qual se desenvolve um grupo social”, sendo produzido por meio do espaço e do tempo, mediante o exercício de poder por determinados grupos sociais ou indivíduos (Saquet, 2015). Nessa perspectiva, o território deve ser compreendido levando-se em consideração o papel dos múltiplos agentes, das instituições, das demais formas organizativas da sociedade e até mesmo da cultura na configuração do espaço social (Schneider, 2004).

Nesse sentido, a abordagem do SIAL pode ser melhor compreendida dentro dessa perspectiva de análise. Portanto, para além das abordagens econômica e social, buscou-se ampliar o entendimento da configuração de um território, englobando as dimensões da economia-política-cultura-natureza (E-P-C-N) propostas por Saquet (2009). A análise E-P-C-N considera o movimento e a relação recíproca entre as dimensões sociais do território, que são seus aspectos econômicos, políticos e culturais. Além disso, os três aspectos estão intimamente ligados à dinâmica da natureza exterior ao homem. Essa combinação de determinações sociais somadas à natureza influenciam na apropriação e produção territorial (Saquet, 2005; Vale, Saquet, \& Santos, 2005). Como o SIAL depende da vinculação ao território, envolvendo principalmente as questões econômicas e culturais, justifica-se a conexão entre as abordagens.

Por conseguinte, admite-se que combinar as perspectivas do SIAL com uma abordagem ampliada do território pode trazer avanços analíticos importantes. Para tentar evidenciar essa situação, optou-se por estudar o município de Marialva, no norte do estado do Paraná (PR). O município parece enquadrar-se no âmbito das duas perspectivas pois vários aspectos econômicos, culturais e políticos convergiram para a transformação do município em Capital da Uva Fina. O título foi aprovado pela lei n ${ }^{\circ} 16.231$ de 28 de agosto de 2009 pela Assembleia Legislativa do Paraná. Isso ocorreu devido ao fato de o município possuir a maior área destinada à cultura da uva no estado em 2008, cerca de 1.550 hectares, com $40 \%$ do total produzido no estado (Assembleia Legislativa do Estado do Paraná [ALEP], 2009; Almeida \& Serra, 2012; Sistema IBGE de Recuperação Automática [SIDRA], 2014). Além disso, em junho de 2017, foi concedida a Indicação Geográfica, na modalidade de Indicação de Procedência, para as uvas finas de mesa de Marialva (Instituto Nacional de Proteção Intelectual [INPI], 2017).

Diante do exposto, o objetivo do presente trabalho é compreender as ações e os atores que configuram Marialva como um território produtor de uva fina. De forma específica, buscou-se identificar historicamente as ações que configuram o município como território, descrever as características que configuram a produção de uva fina como um SIAL e discutir os desdobramentos dessa análise. Para isso, o referencial teórico apresenta discussões sobre território e desenvolvimento territorial e posteriormente sobre SIAL. Logo após, são apresentados os procedimentos metodológicos, seguidos da análise e das conclusões do estudo.

\section{Território e Desenvolvimento Territorial}

O conceito de território passou a ser bastante discutido no Brasil a partir da década de 1990, contudo, ainda persiste certa confusão sobre suas fronteiras (Souza, 2009). Essa confusão ocorre devido à grande amplitude do conceito, pois além de ser central para a Geografia, outras áreas também se interessam por ele, como a Ciência Política, a Economia, a Antropologia, a Sociologia e a Psicologia, embora cada uma apresente um enfoque centrado em determinada perspectiva (Haesbaert, 2004).

Ao longo do tempo, o território assumiu significados distintos para diferentes sociedades. A ideia de território já era discutida desde o século XV, ligada a questões políticas de dominação de determinada área de terras, sendo associada ao Estado. Nos séculos XVII e XVIII, o território passa a ser visto como um receptáculo das atividades econômicas do homem. Neste ínterim, natureza e Estado assumem centralidade na compreensão do território, sendo as relações existentes permeadas pelo poder. É a partir das reflexões sobre as relações de poder que o conceito de território se altera (Saquet, 2015).

A partir de 1980, com a intensificação do fenômeno da globalização, no qual os meios de circulação e informação se efetivam, o nível local-regional passa a ser visto como parte de uma rede. Configura-se uma nova 
dinâmica de posição relacional e o conceito de território adquire novos significados em diferentes abordagens e concepções (Haesbaert, 2004; Saquet, 2015).

Atualmente, há uma grande expansão e qualificação dos estudos no Brasil com o intuito de compreender os fenômenos e processos sociais e territoriais, envolvendo as redes de circulação e comunicação, a identidade e as relações de poder. De modo geral, Saquet (2015) vincula essa expansão a cinco principais abordagens: (1) os estudos de Raffestin, evidenciando aspectos econômicos e políticos do território e da territorialidade; (2) as discussões de Deleuze e Guattari, com as dimensões da cultura e da política; (3) com Gottmann e Sack, no campo da geopolítica; (4) nos estudos de fenômenos e processos de desenvolvimento territorial, feitos por diversos autores, dentre eles Bagnasco, Quaini e Dematteis; e (5) nas reflexões de Milton Santos, englobando uma compreensão de configuração territorial, dos fixos, fluxos e do território usado.

A presente pesquisa apresenta maior foco na quarta perspectiva, nos moldes do desenvolvimento territorial, proporcionada sobretudo pela abordagem do SIAL. Entretanto, pretende-se ampliar essa visão por meio da análise E-P-C-N. Essa análise envolve uma abordagem material e imaterial, histórica e multiescalar do desenvolvimento e do território, da desterritorialização e reterritorialização, reconhecendo descontinuidades, desigualdades, ritmos, temporalidades e territorialidades (Saquet, 2015). Percebe-se a complexidade da análise que engloba diversos conceitos, sendo necessário discutir cada ponto separadamente para melhor entendimento.

Em primeiro lugar, entende-se que os territórios possuem diferenças de acordo com os grupos de poderes que agem sobre ele. Esses grupos estampam suas características e objetividades, moldando o território conforme suas relações, que ocorrem nas dimensões da economia, política e cultura (Teixeira \& Andrade, 2010). Essas três dimensões são e estão relacionadas, condicionando-se de maneira indissociável. O reconhecimento dessa articulação é necessário para superar os limites de cada abordagem isoladamente (Vale et al., 2005).

Além disso, as relações que existem entre essas dimensões sociais do território são aliadas aos componentes naturais, externos à vida orgânica do homem. O homem mantém relações diárias entre si, com sua natureza interior e com a natureza inorgânica para sobreviver biológica e socialmente (Vale et al., 2005). Nessa perspectiva, Mariani e Arruda (2010) argumentam que o território é uma categoria de análise produzida por ações políticas e socioeconômicas. Emerge como um produto da construção de uma sociedade, num processo de apropriação de uma porção do espaço por uma coletividade. Assim, justifica-se a análise E-P-C-N, uma vez que ela permite uma ideia ampliada da formação do território, considerando as relações materiais e imateriais existentes.

De acordo com Saquet (2015), as relações materiais de formação do território envolvem, entre outros, o planejamento e a produção de mercadorias. A abordagem imaterial é centrada na relação espaço-tempo, sendo a noção de espaço socialmente construída, objetiva e subjetivamente. $\mathrm{O}$ autor apresenta uma análise (i)material, sendo material e ao mesmo tempo simbólica. Nesse contexto, o território é visto como um campo de forças que envolvem obras e relações sociais: econômicas, políticas e culturais, que são historicamente determinadas.

Com relação à concepção multiescalar, esta envolve diferentes níveis escalares, como nos níveis do indivíduo, da casa, do bairro, do estado, do país e em nível internacional. Os processos sociais são multiescalares e multitemporais, ocorrendo em um movimento histórico e relacional a um só tempo, com continuidades e descontinuidades (Saquet, 2009).

A questão da territorialidade designa a qualidade que o território adquire com a sua utilização ou apreensão pelo ser humano, tanto individuais quanto coletivas. A territorialidade está intimamente ligada ao modo como as pessoas utilizam a terra, como elas próprias se organizam no espaço e como elas dão significado ao lugar. Nesse caso, podem ocorrer processos constantes e concomitantes de desterritorialização e reterritorialização, gerando novas territorialidades e novos territórios que contêm características dos 
territórios e das territorialidades anteriores (Saquet, 2009). Observa-se, então, seu caráter mutável, porém sempre com uma estreita ligação com o passado.

Os territórios se transformam, dependendo do ritmo das novas técnicas (Raffestin, 2009). As técnicas e tecnologias, em conjunto com os instrumentos e máquinas e com o conhecimento, a ciência e o saber popular, são vistos como mediações entre o homem e o espaço na apropriação e produção territorial (Saquet, 2009). Para Raffestin (2009, p. 26), a produção territorial é um processo complexo, no qual "o ator projeta no espaço um trabalho, isto é, energia e informação, adaptando as condições dadas às necessidades de uma comunidade ou de uma sociedade".

Partindo de todos esses elementos, Saquet (2015, p. 131) trata da articulação territorial, que engloba "uma combinação de territorialidades e temporalidades, de mudanças e descontinuidades, no tempo e no espaço, através do trato da processualidade histórica e transescalar". O autor afirma que a abordagem territorial pode contribuir para o planejamento e gestão do desenvolvimento de forma mais democrática e participativa, gerando práticas sociais solidárias e transparentes da gestão do território.

Para tratar das questões do desenvolvimento local, Dematteis (2005), em conjunto com outros pesquisadores italianos, desenvolveu uma abordagem analítico-operativa denominada Slot (Sistemas Locais Territoriais), que se propõe a interpretar as relações existentes entre os sujeitos e o território, as potencialidades do território local, a governança e o desenvolvimento. Por meio do Slot busca-se não somente explicar um sistema territorial já existente, mas os indícios e pré-condições para construir um processo territorial capaz de contribuir com o desenvolvimento. Nessa visão, para desenvolver determinado território, deve-se entender a capacidade autogovernativa dos sujeitos e sua interação com o capital territorial local.

Como o desenvolvimento territorial abordado aqui trata de uma abordagem ampla, a participação social e a organização local são relevantes para desencadear processos de desenvolvimento em regiões periféricas, principalmente aquelas caracterizadas pela presença da agricultura familiar (Rambo \& Filippi, 2009). Entende-se por desenvolvimento territorial as ações, mecanismos, estratégias e políticas endógenas que são desencadeadas por atores locais em interação com diferentes escalas de poder e gestão, construindo ou reforçando territórios com novos usos políticos e econômicos (Rambo, Filippi, \& Ruckert, 2007; Freitas, Freitas, \& Dias, 2012).

A organização local depende do auxílio de políticas públicas para sua efetivação, principalmente quando se trata da agricultura familiar (Santos, 2011). O Estado como fomentador de iniciativas locais abre possibilidades de atuação mais ativa dos agentes locais, que estão mais próximos da realidade local e, por isso, tendem a tornar os processos de desenvolvimento mais adequados (Rambo \& Filippi, 2009). A dimensão política é expressiva, tanto quanto a econômica e a cultural, sendo que, juntas, elas alteram a organização territorial: o trabalho, a produção, a tecnologia, o consumo e as relações sociais (Santos, 2011).

Além disso, considera-se a questão da identidade dos sujeitos, que é inerente à formação de cada território num contexto de relações sociais com o ambiente externo à vida em sociedade. A identidade é um patrimônio territorial que pode ser potencializado em projetos e programas que visem sua preservação e valorização. O patrimônio identitário envolve o saber-fazer, as edificações, os monumentos, dialetos, crenças, arquivos históricos, as empresas, organizações políticas, entre outros (Saquet \& Briskievicz, 2009).

De modo similar, Veiga (2005) propõe que a perspectiva territorial é importante para o desenvolvimento rural, principalmente por causa de duas questões: (1) a necessidade inevitável de articulação institucional de caráter microrregional e intermunicipal e (2) a construção de uma imagem de marca identitária, relacionada a valorização do patrimônio natural, histórico e cultural de determinada área geográfica.

O território passa a ser visto e compreendido como a nova unidade de referência e mediação das ações do Estado e o enfoque no desenvolvimento territorial torna-se, portanto, um modo de ação que valoriza os atributos políticos e culturais das comunidades e dos atores sociais ali existentes (Schneider, 2004). A partir desta concepção mais ampla do território, espera-se conseguir um maior aprofundamento dos estudos no contexto do SIAL. O próximo tópico apresenta um panorama dessa discussão. 


\subsection{Sistema agroalimentar localizado}

O SIAL teve origem com os estudos franceses do Centro de Cooperação Internacional em Pesquisa Agronômica para o Desenvolvimento (CIRAD) em 1996. A partir daí, começa-se a dar importância ao espaço, destacando o território como um ator histórico e social que é necessário para o entendimento de como os sistemas agroalimentares se estruturam em âmbito local. Em 1998, o seminário Sistemas Agroalimentares Localizados e Construção de Territórios, com a reunião de alguns órgãos como o CIRAD, o Instituto Nacional de Pesquisa Agronômica (INRA) e o SUPAgro Montpellier, formam um Grupo de Interesse Científico Interinstitucional (GIS SYAL) (Muchnik, Cañada, \& Salcido, 2008; Specht \& Ruckert, 2008).

Desde então, as discussões têm evoluído, bem como o conceito e a abrangência do tema. Muchnik et al. (2008) asseveram que a aquisição de conhecimentos sobre o SIAL ainda não se estabilizou e, para avançar, é preciso construir uma abordagem baseada na relação homem, produto e território. Essa relação deve ser feita a partir de uma perspectiva integradora, na qual o território é visto pelo homem como um espaço identitário em que exista um sentimento de pertencimento. A partir dessa identificação, a coordenação das atividades inclui questões de solidariedade, utilizando-se do capital social existente no local e ligação com o produto, que depende das questóes de especificidade de ativos, qualidade e apelo geográfico. Por fim, os consumidores devem entender as referências culturais existentes, valorizando as tradições por meio de aspectos simbólicos.

Apesar das inter-relações evidentes entre homem, produto e território, para fins metodológicos, faz-se um esforço de trabalhar individualmente o papel de cada um deles na constituição do SIAL. De modo específico, com relação ao homem, discute-se que o SIAL é um espaço elaborado, construído socialmente e, em decorrência disso, marcado por características culturais e institucionais (Diáz-Bautista, 2001). Nesse ambiente, a troca de informação, conhecimentos, mão de obra ou outros meios de cooperação entre os indivíduos constrói um capital social que é formado tanto pelo componente social quanto pelo econômico, ligado às vantagens econômicas obtidas pelos indivíduos por meio do capital social (Requier-Desjardins, 1999).

Moraes e Schneider (2010) informam que a constituição do SIAL é feita com base no conjunto das relações sociais de trabalho e produção. Por isso, há uma relação de proximidade entre os modos de fabricação dos produtos e as preferências dos consumidores. A proximidade com o consumidor não é necessariamente física, pode também ser simbólica, no sentido de apreciação e valorização do produto. Essa valorização decorre do savoir-faire e da capacidade dos atores para usar os recursos específicos locais coletivamente, culminando em produtos diferenciados ou inovadores (Boucher, Requier-Desjardins, \& Brun, 2010).

Entra em cena o constructo produto. Os indivíduos criam produtos utilizando-se dos recursos locais específicos que são inerentes a um território. A estruturação do SIAL ocorre, então, quando a qualidade dos produtos é ligada ao seu território produtivo. Nesse caso, os ativos específicos do território são utilizados de diversas formas por meio da produção coletiva, destacando-se a preocupação ambiental e a valorização da cultura e do saber-fazer local (Specht \& Ruckert, 2008).

Os ativos específicos são produzidos por meio dos laços construídos com o território. Os laços podem ser resumidos em três aspectos: (1) laços históricos, formados pelas origens e referências identitárias das pessoas, que ocorrem por meio do sentimento de pertencimento ao território e a uma história; (2) laços materiais, que são os aspectos físicos, como solo, relevo e paisagens, os cuidados ambientais, as técnicas produtivas, as características dos produtos e a dificuldade de deslocamento territorial de uma produção primária; e (3) laços imateriais, que também podem ser chamados de patrimônio intangível, como a cultura, seus sabores, saberes, tradições e a imagem do território criada pelos indivíduos (Fourcade, Muchnik, \& Treillon, 2005).

Por fim, abordando a questão do território, a constituição do SIAL ocorre quando é feita a conjugação entre as redes de relações, a cultura, as instituições, a população, seu saber-fazer, seus produtos e seus padrões alimentícios. Essa junção forma um sistema agroalimentar em determinada escala espacial (Muchnik \& Sautier, 1998). Realça-se aqui o papel do Estado, que, em conjunto com as articulações entre os produtores e 
a rede institucional, constitui ações que possibilitam o desenvolvimento da atividade e, consequentemente, do território (Menezes, 2011).

Em resumo, apresenta-se que a importância do SIAL advém da associação de técnicas, produtos típicos, estilos de produção, território, recursos naturais, ações coletivas e organização das atividades. Dentro dessa associação, somada à vontade de cooperar pode-se alcançar a eficiência, por meio de processos de ação coletiva. A proximidade entre os agentes, o impacto do ambiente de confiança e o sentimento de identidade comum entre eles permitem custos reduzidos de transação (Malafaia et al., 2007).

Nota-se que as perspectivas de território e de SIAL versam sobre o desenvolvimento territorial, que por sua vez, necessita de combinações econômicas, políticas e culturais para se configurar. A tríade homemproduto-território é sustentada nas dimensões da economia, política, cultura e natureza. Somente com ações inter-relacionadas nessas quatro dimensões torna-se possível o processo valorização de produtos e saberes vinculados ao território, condição para constituição de um SIAL. Portanto, essas preocupações podem contribuir para uma análise mais ampla das potencialidades locais e dar subsídios para um planejamento territorial mais efetivo, beneficiando os atores envolvidos.

\section{Procedimentos Metodológicos}

Para o alcance do objetivo proposto, a presente pesquisa classificou-se como descritiva, com abordagem qualitativa, uma vez que se buscou descrever com exatidão os fatos e fenômenos de determinada realidade (Triviños, 2008), com uso de dados secundários por meio da pesquisa documental. Foram consultados documentos que tratam da viticultura no município, a saber: relatórios, documentos institucionais, banco de dados, livros, teses e o inventário turístico do município de Marialva. Esse levantamento de materiais foi essencial principalmente para compreender períodos antigos da história do município e as ações e os atores que se articularam para a configuração da produção de uva fina como um SIAL.

Os dados secundários foram analisados mediante análise documental, acatando-se a sugestão feita por Merriam (1998): após a certificação da origem dos documentos e de sua autenticidade, os mesmos passaram por uma criteriosa e sistemática análise de conteúdo, visando descrevê-los o máximo possível. Merriam (1998) ainda afirma que a técnica de análise documental permite analisar não só os fenômenos sociais, quando e como se produzem, mas as manifestações que estes fenômenos registram e as ideias elaboradas a partir deles. A partir das duas principais abordagens teóricas utilizadas, sobressaíram para a análise os elementos contemplados pela abordagem proposta por Saquet (2009): economia, política, cultura e natureza, bem como os aspectos contemplados pela abordagem do SIAL: homem, produto e território, os quais serão apresentados no próximo item.

\section{Marialva como Território Produtor de Uva Fina}

A análise apresenta as ações e atores que configuram o município como um território produtor de uva fina, envolvendo as questões de economia, política, cultura e natureza. Essas quatro dimensões são apresentadas de forma interligada, evitando, assim, que nenhum aspecto importante seja ignorado na análise das relações de poder existentes em determinado território (Saquet, 2009). Num segundo momento, são discutidas as características que configuram a produção de uva fina como um SIAL, finalizando com uma articulação entre as duas abordagens.

Em primeiro lugar, destaca-se a importância da análise documental e cronológica, visando uma perspectiva histórica, para entender o processo de configuração do território, conforme defende Saquet (2015). No caso de Marialva, esta foi inicialmente idealizada em 1940 pela Companhia de Terras Norte do Paraná como um patrimônio ao lado da estrada que liga outras duas cidades daquele estado, Mandaguari e Maringá. A venda 
de lotes teve grande êxito e atraiu muitas pessoas que tinham o objetivo de se dedicar à cultura do café, para a qual o clima subtropical e a terra roxa eram indicados. O nome do município foi dado em homenagem ao Marquês de Marialva, D. Pedro de Alcântara Menezes (Ferreira, 2006). Em seis anos, seus moradores iniciaram movimentos que culminaram na elevação a Distrito de Mandaguari pela Lei Estadual $n^{\circ} 02 \mathrm{em}^{\circ}$ de outubro de 1947, sendo emancipado em 14 de novembro de 1951 por meio da Lei ${ }^{\circ} 790$ (Inventário Turístico Marialva-PR, 2015).

O município de Marialva está localizado na região Norte do estado do Paraná, conforme destaca a Figura 1.

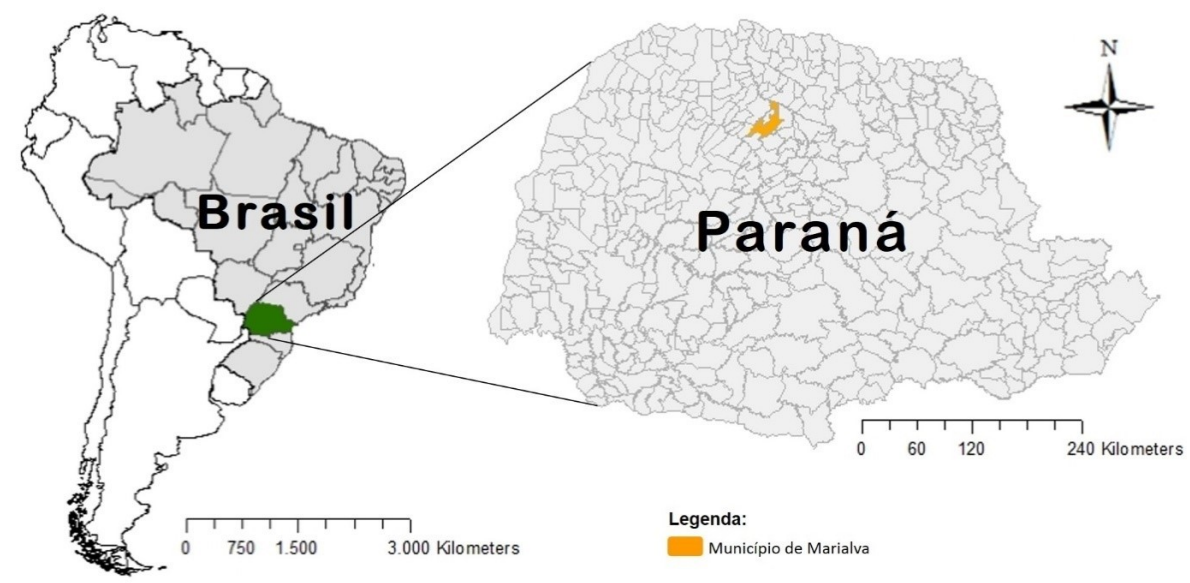

Figura 1: Localização do município de Marialva-PR

Fonte: Elaborada a partir do Ministério dos Transportes (2010).

O crescimento populacional da região foi bastante significativo entre os anos de 1920 e 1960, devido a três importantes fatores: a expansão da cafeicultura paulista, a existência de grandes extensões de terra roxa no Norte do Paraná e a conjuntura econômica nacional após a crise de 1929. O avanço dos cafezais culminou na abertura de estradas e no surgimento de vilas e cidades, de máquinas de beneficiamento e de empresas especializadas em exportação de café, modificando a paisagem existente. Nas décadas de 1930 e 1940 chegam à região de Marialva os primeiros produtores de café, na maioria descendentes de japoneses e italianos (Alves \& Pelegrini, 2010).

A partir da década de 1960 inicia-se um processo de modernização da agricultura brasileira, que trouxe consigo transformações na política, na economia e na sociedade. Na década de 1970, dois fatores contribuíram para a mudança da cultura agrícola no estado: o primeiro foi um fator desestimulante, a ocorrência de um evento climático trágico para a agricultura, conhecida como geada negra; o segundo foi a substituição da cultura predominante na região, na qual as culturas perenes foram substituídas por extensas áreas mecanizadas (Instituto Paranaense de Desenvolvimento Econômico e Social [IPARDES], 2002; Almeida \& Serra, 2012).

Nessa época houve grande êxodo rural por parte dos produtores que não conseguiram se modernizar. Em Marialva, houve um aumento significativo do número de pequenas propriedades rurais que, a partir da década de 1980, começaram a implantação da cultura da uva, e desde então conseguem ocupar elevado volume de mão de obra e gerar lucros consideráveis, revertendo o êxodo rural no município. Os pequenos produtores viram vantagens na produção da uva, pois o espaço destinado a ela era muito menor do que o exigido por outras, sendo que o módulo rural para a produção gira em torno de 4 a 5 mil metros (Almeida \& Serra, 2013). Existe elevada utilização de mão de obra, sendo em média quatro pessoas por hectare, o que favorece a agricultura familiar para esta cultura (Sato \& Roberto, 2004).

Considerando o proposto por Saquet (2009), de que a análise territorial deve estar centrada nos atores locais e suas relações e não apenas o território em si, uma vez que tais relações que vão territorializar espaços, imprimindo-lhes uma determinada territorialidade conforme suas características e objetivos, é 
necessário destacar que o crescimento significativo da viticultura no município contou com três agentes com importantes papéis: a colônia japonesa, o Instituto Paranaense de Assistência Técnica e Extensão Rural (EMATER) e o governo municipal. Com relação à colônia japonesa, destaca-se que em todo o estado do Paraná, o cultivo da uva criou raízes nas localidades onde havia núcleos mais fortes da colônia japonesa, como Assaí, Uraí, Bandeirantes e Marialva. Nessa última cidade, as primeiras produções na década de 1960 eram exclusivamente de propriedade de descendentes de japoneses, provenientes da região de São Miguel Arcanjo no estado de São Paulo, cujo clima mais frio permitiu a adaptação da uva. Ressalta-se ainda que o comportamento muito reservado dos japoneses não disseminava os conhecimentos sobre a cultura da uva. Isso se deve ao contexto histórico de preconceito e discriminação sofrido pela população japonesa que migrou para o Brasil, justificando o fechamento dessas comunidades. Por esse motivo, outros grupos étnicos tiveram dificuldade em aprender sobre a cultura da uva (Almeida $\&$ Serra, 2012).

Segundo Almeida e Serra (2012), o crescimento econômico dessa cultura foi influenciado principalmente por dois fatores: as pessoas e o lugar. Em 1980 Marialva conseguiu um fato inédito, colocar uvas no mercado durante o período de Natal, devido a fatores climáticos. As características climáticas da região favorecem a realização de duas safras anuais de uva, a safra normal e a safrinha (Hiera \& Silveira, 2011). A combinação entre as pessoas que tem conhecimento sobre seu trabalho e cuidados com o cultivo e as características geográficas da região culminaram no sucesso da viticultura, fato que foi-se disseminando entre as cidades vizinhas, gerando o aumento da produção (Almeida \& Serra, 2012).

Para auxiliar nessa disseminação, entra em cena o papel da EMATER que, na época, tinha a função de diversificar as atividades do meio rural para evitar o êxodo. Os técnicos começaram a buscar conhecimento junto a uma família da colônia japonesa e perceberam que a cultura era rentável, por isso começaram a estimular a viticultura no município. Em 1987 foi realizado o I Encontro de Viticultores na Câmara Municipal, reunindo 180 produtores que, em sua maioria, não possuíam conhecimento sobre o assunto. Salienta-se que até os produtores mais antigos não tinham conhecimentos técnicos, seu trabalho era desenvolvido por processos de tentativa e erro, através de experiências próprias (Almeida \& Serra, 2012).

$\mathrm{O}$ fortalecimento da viticultura no município ocorreu também devido a ajuda de alguns programas do governo, como o Programa Nacional de Apoio à Agricultura Familiar (PRONAF) ${ }^{[\mathrm{i}]}$, que financia a juros mais baixos e o projeto Paraná 12 meses ${ }^{[i i]}$, que forneceu recursos para melhorar a infraestrutura das parreiras; e os incentivos do governo municipal. Em princípio, o governo municipal auxiliou no cascalheamento de carreadores para facilitar o escoamento da produção. No entanto, a partir do ano 2000 o apoio foi mais significativo (Almeida \& Serra, 2012): Foi criado em 2005 o Parque da Uva, com uma área de 127.615 metros quadrados, destinado à realização dos eventos ligados à viticultura, como a Festa da Uva Fina. Dentro do parque encontra-se a Casa da Uva, o Restaurante Hiromo Toyohara e um pavilhão que acomoda aproximadamente 2500 pessoas (Inventário Turístico Marialva-PR, 2015).

Além disso, em 2004, o governo municipal criou a Lei da Uva Verde, que pune produtores que vendem frutos com baixo teor de açúcar. Essa lei está de acordo com a regulamentação do Ministério da Agricultura que padroniza produtos agrícolas para comercialização. A fiscalização realizada pelo Poder Público Municipal ajudou a melhorar a imagem da uva de Marialva perante os principais mercados consumidores (Almeida \& Serra, 2012).

Devido a esse histórico de desenvolvimento, a importância da uva foi reconhecida pela população e virou objeto de propaganda. Em 2004, foi construído um monumento em forma de cacho de uva na entrada da cidade (Almeida \& Serra, 2012) e, em 2014, foi construído outro monumento, o portal "Parreiral de Uva" (Prefeitura Municipal de Marialva, 2014), ilustrados na Figura 2. Essas e outras ações tentam tornar o município atrativo para a visita de turistas, por esse motivo, a Secretaria de Turismo em parceria com o Sebrae desenvolveu em 2015 um Inventário Turístico nos moldes da metodologia do Ministério do Turismo (Inventário Turístico Marialva-PR, 2015). 


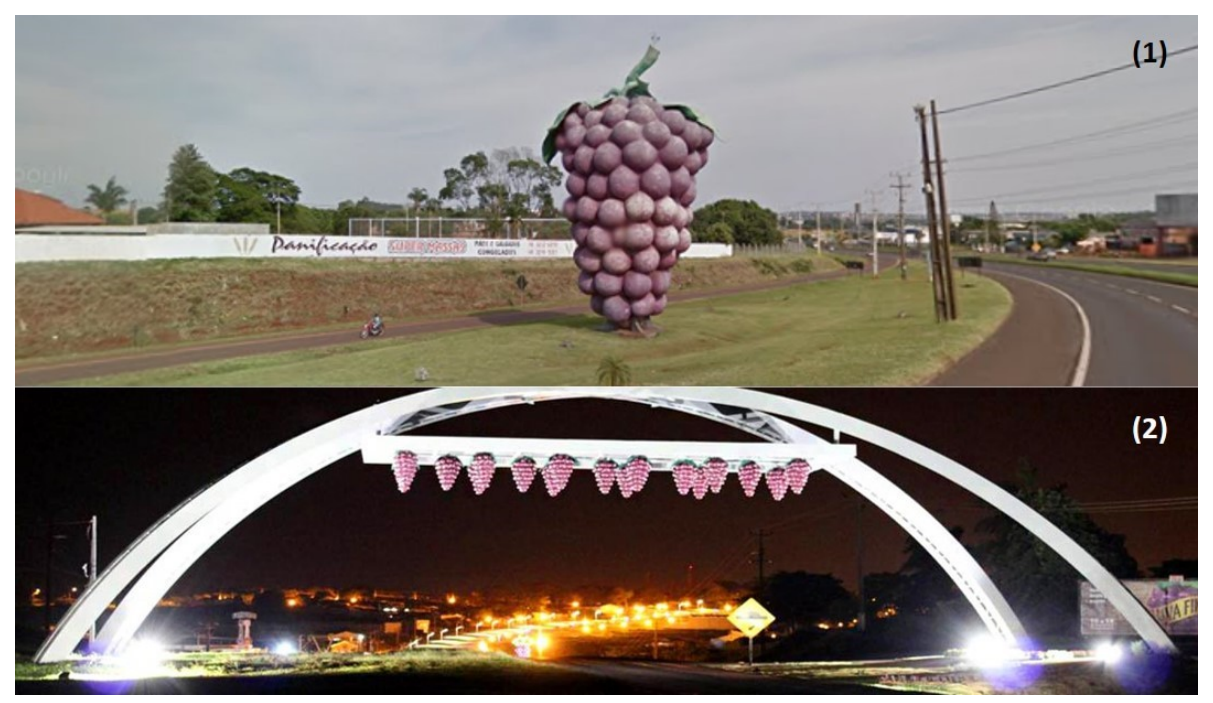

Figura 2: Monumento "Cacho de Uva" (1) e Portal "Parreiral de Uva" (2) Fonte: Google Street View (2011) e Prefeitura Municipal de Marialva (n.d.).

Outro ator importante em todo o processo foi a Associação Norte Paranaense de Estudos em Fruticultura (ANPEF), que desde 1996 tem o objetivo de unir produtores para definir estratégias de expansão da atividade frutícola, priorizando o cultivo de uvas em função de sua importância no contexto da economia local. A ANPEF realiza pesquisas em parceria com diversas instituições de ensino e pesquisa (Almeida, 2010).

A população do município está estimada em 34.388 habitantes (Instituto Brasileiro de Geografia e Estatística [IBGE], 2015). São mais de 900 produtores residentes em aproximadamente 800 hectares de produção contínua, que geram mais de seis mil empregos diretos e indiretos, com um faturamento bruto anual médio de R \$ 80 milhões (Agência Sebrae de Notícias Paraná [ASN], 2015). A Tabela 1 mostra a quantidade produzida de uva e o valor da produção no Paraná e em Marialva.

Tabela 1: Quantidade produzida de uva e valor da produção entre 2000 e 2014

\begin{tabular}{l|l|l|l|l|l}
\hline & \multicolumn{3}{|l|}{$\begin{array}{l}\text { Quantidade produzida de Uva } \\
\text { (Toneladas) }\end{array}$} & \multicolumn{2}{l}{$\begin{array}{l}\text { Valor da produção (Mil } \\
\text { Reais) }\end{array}$} \\
\hline & & & $\begin{array}{l}\text { \%em } \\
\text { relação } \\
\text { ao } \\
\text { estado }\end{array}$ & Paraná & Marialva \\
\hline 2000 & 80.407 & 24.650 & 30,66 & 71.241 & 21.840 \\
\hline 2001 & 97.357 & 41.810 & 42,95 & 74.012 & 37.629 \\
\hline 2002 & 99.118 & 35.100 & 35,41 & 90.135 & 31.590 \\
\hline 2003 & 102.974 & 44.900 & 43,60 & 114.852 & 51.635 \\
\hline 2004 & 96.662 & 33.413 & 34,57 & 96.085 & 33.413 \\
\hline 2005 & 99.253 & 40.600 & 40,91 & 92.238 & 36.540 \\
\hline 2006 & 95.357 & 40.100 & 42,05 & 136.722 & 60.150 \\
\hline 2007 & 99.180 & 40.947 & 41,29 & 129.582 & 59.373 \\
\hline 2008 & 101.500 & 42.808 & 42,18 & 146.115 & 63.142 \\
\hline 2009 & 102.080 & 51.246 & 50,20 & 173.679 & 89.681 \\
\hline 2010 & 103.394 & 43.320 & 41,90 & 168.238 & 64.980 \\
\hline 2011 & 83.948 & 21.450 & 25,55 & 146.667 & 38.610 \\
\hline 2012 & 78.614 & 18.876 & 24,01 & 146.765 & 24.916 \\
\hline 2014 & 88.402 & 25.800 & 29,18 & 202.113 & 70.176 \\
\hline & & & & & \\
\hline
\end{tabular}

Fonte: SIDRA (2014). 
Apesar da oscilação da quantidade produzida, observa-se que a porcentagem de produção de uvas em Marialva é em média 38\% maior em relação à produção do estado do Paraná. O valor da produção também é bastante significativo, sendo uma cultura altamente rentável, como destaca Almeida (2010), embora o processo produtivo seja difícil devido à fragilidade do produto.

Por fim, destaca-se as parcerias para o desenvolvimento do cultivo da uva no município, como o Projeto Nova Uva, que tem o objetivo de melhorar os índices de qualidade do produto e contribuir para o aumento de competitividade dos produtores do município. O projeto começou em 2014, envolvendo a Prefeitura de Marialva, o Sebrae/PR e a ANPEF (ASN, 2015). Além disso, vários trabalhos científicos são desenvolvidos no sentido de conhecer e melhorar os tipos de uva cultivados na região, como a mutação somática natural Black Star, originada da uva cv. Brasil em uma propriedade de Marialva (Roberto, Assis, Genta, Yamamoto, \& Sato, 2012); a avaliação da qualidade das uvas (Roberto et al., 2002); estudos sobre as exigências climáticas da videira (Hiera \& Silveira, 2011); avaliação nutricional e qualidade dos frutos (Tonin et al., 2009), entre outros. Essa dinâmica de pesquisa e desenvolvimento parece impulsionar o ritmo da produção territorial da uva, conforme defende Raffestin (2009) e Saquet (2009).

Diante do histórico de transformação do município de Marialva em um território produtor de uva fina, percebe-se o envolvimento de vários aspectos que convergiram para isso. Foi possível perceber diversas ações e relações entre os agentes especificados envolvendo todos os aspectos da análise E-P-C-N proposta por Saquet $(2009 ; 2015)$. Em primeiro lugar, com relação aos aspectos da natureza, nota-se que a geada negra, que devastou as plantações, começou um processo de desterritorialização da cultura do café. Mais tarde, a reterritorialização da uva fina ocorreu, considerando, entre outros fatores, a fertilidade da terra roxa e o clima favorável a essa nova cultura, com a realização de duas safras anuais.

Aliado a isso, no início do processo aparece o aspecto econômico envolvendo a modernização da agricultura brasileira que, por falta de capital para grandes investimentos, tornou viável as pequenas propriedades e culturas que pudessem ser cultivadas nessas propriedades, como o caso da uva fina. Ainda considerando o aspecto econômico, apresenta-se a importância que a atividade ganhou no decorrer dos anos, fazendo com que um grande número de empregos fosse criado, trazendo rentabilidade aos agricultores. A dependência econômica da região torna-se um aspecto considerável para a proliferação da atividade, ocasionando o título de Capital da Uva Fina.

Considerando o aspecto da cultura, observa-se o papel da colônia japonesa que trouxe conhecimentos que tornaram possível o início do processo produtivo da uva no município. Nesse quesito, dois pontos merecem destaque, um negativo e um positivo como mostrou Almeida e Serra (2012): o ponto negativo é que o comportamento reservado dos japoneses retardou o início da disseminação da cultura. O ponto positivo é que os japoneses têm o hábito da dedicação ao trabalho, sendo bastante cuidadosos com cultivares, justamente o que a cultura da uva necessita.

Outro aspecto cultural que auxilia na perpetuação do território é o reconhecimento da importância da atividade por parte da população. Isto parece estar se intensificando em Marialva, principalmente a partir do apoio efetivo do governo municipal. Neste caso, envolve-se o aspecto político, que também foi importante em todo o processo. No começo da disseminação da cultura da uva o papel da EMATER foi essencial, percebendo a rentabilidade da cultura, fazendo a ponte entre produtores japoneses com os demais e participando das ações desenvolvidas pelo governo municipal. A EMATER ainda auxiliou na formação da ANPEF, que aproxima os produtores e o poder público. Salienta-se também o papel das políticas públicas nacionais, como o Pronaf; estaduais, como o Projeto Paraná 12 meses; e municipais, como a criação do Parque da Uva e a Lei da Uva Verde.

Contudo, adverte-se para o envolvimento tardio do governo municipal. Como apresentado anteriormente, a disseminação da cultura da uva data da década de 1980, no entanto, somente a partir do ano 2000 o governo municipal começa a participar mais efetivamente. Esse fato retardou o processo de 
reconhecimento territorial do município como produtor de uva fina, consequentemente, admite-se que o desenvolvimento territorial poderia estar mais avançado se essa participação tivesse começado antes.

Enfim, vale ressaltar que os aspectos apresentados não podem ser analisados separadamente e não possuem uma ordem cronológica ou sequencial. A dinâmica da produção territorial e da articulação territorial no caso de Marialva foi realizada de forma complexa, combinando acontecimentos econômicos, políticos e culturais, conforme apresenta Saquet (2009).

Apresenta-se ainda que o território da uva mantém ligações com a cultura cafeeira, pois utiliza-se das profundas transformações que ocorreram na paisagem da região, principalmente as estradas e a mão de obra, que foi adaptada. A própria crise na produção do café impulsionou a busca por novas culturas, porém esta não deixou de existir, fato condizente com a proposta de Saquet (2009) sobre territorialidades.

Por fim, percebe-se que o desenvolvimento territorial ocorreu por conta da organização local, das estratégias dos atores envolvidos e, mais tardiamente, das políticas públicas que formaram um patrimônio identitário ao município, de acordo com as perspectivas apresentadas por Rambo et al. (2007), Santos (2011), Freitas et al. (2012) e Saquet e Briskievicz (2009). Essas evidências estão de acordo com as características do SIAL, discutidas no próximo tópico.

\subsection{Características da produção de uva fina em Marialva sob a perspectiva do SIAL}

Como percebido anteriormente, o município de Marialva pode ser visto como um território produtor de uva fina. Entretanto, para caracterização do SIAL, parte-se da proposição de Muchnik et al. (2008) de construir uma abordagem baseada na relação homem, produto e território. A questão do território foi demonstrada no tópico anterior enaltecendo a conjugação do aspecto cultural, com a colônia japonesa e o papel do Estado, articulando políticas de desenvolvimento territorial para a criação do sistema agroalimentar da uva. Essas ações dão suporte ao aspecto territorial apontado por Muchnik e Sautier (1998) e Menezes (2011).

Acrescenta-se a essa discussão o sentimento de pertencimento ao território, construído por meio de laços materiais e imateriais formados ao longo do tempo, como indica Fourcade et al. (2005). Esse parece ser o caso de Marialva, que cada vez mais se reconhece como capital da uva fina, pela criação do Parque da Uva, pela realização da Festa da Uva, pelos monumentos na entrada da cidade, bem como pelas atividades desenvolvidas pelos atores responsáveis pela disseminação da cultura na cidade, como os produtores, a ANPEF e o governo municipal. Essa afirmação do território também pode ser percebida pela associação da qualidade do produto perante os principais mercados consumidores, que vem ocorrendo com a uva de Marialva, segundo Almeida e Serra (2012).

O produto aparece, então, com fortes ligações territoriais por dois principais motivos: as características geográficas e o conhecimento construído ao longo do tempo. Como já discutido, as características geográficas, como solo e clima, contribuem para a produção da uva em duas safras anuais. Com relação ao conhecimento, o agrônomo Werner Genta, membro da ANPEF, relata que a fruta de melhor qualidade do Paraná está no município de Marialva, em virtude do histórico de conhecimento aplicado na atividade. Nesse contexto, a mão de obra especializada utilizada em pequenas propriedades, que é o caso de Marialva, traz vantagens relacionadas aos cuidados nos tratos culturais (Almeida \& Serra, 2013).

A uva fina de mesa é um produto que requer cuidado manual e, por isso, utiliza grande quantidade de mão de obra especializada (Sato \& Roberto, 2004). Para que o produto mantenha a qualidade, há no município dois fatores relacionados à mão de obra que contribuem para isso: um sistema de parceria e o trabalho familiar. $\mathrm{O}$ sistema de parceria funciona da seguinte maneira: os produtores com área acima de 2 hectares dividem as tarefas com parceiros. O proprietário da terra fica responsável pela compra de insumos, adubos e pelos materiais necessários à colheita. O parceiro entra com a mão de obra e os equipamentos necessários ao trabalho. A divisão do faturamento total é de $65 \%$ para o proprietário e $35 \%$ para o parceiro, que pode morar na propriedade, porém não recebe remuneração (Almeida \& Serra, 2012). O trabalho familiar é essencial 
para a videira, que necessita de cuidados diários, absorvendo o trabalho de toda a família, que se especializou continuamente.

Observa-se que o constructo produto, que é desenvolvido com base em quesitos de qualidade, está inteiramente ligado ao constructo homem, devido à importância da mão de obra, que é o principal fator de produção. Outro aspecto que merece destaque é o trabalho da mulher no cultivo da uva. Em diversas propriedades, elas realizam todas as atividades relacionadas aos tratos culturais, que são as fases de amarração, capação, desneteamento, pente, raleio, limpeza e colheita. Ademais, Almeida (2010) relata que ocorre algo curioso quanto à vontade dos jovens em Marialva, pois há um grande número de produtores jovens e os adolescentes indicam que pretendem permanecer no município e dar continuidade ao trabalho dos pais, características não muito comuns às atividades agropecuárias.

Considera-se a discussão apresentada por Saquet (2009) de que o território é objetivo-material e subjetivoimaterial ao mesmo tempo, uma vez que é o produto das articulações sociais, das tramas que envolvem as construções (formas espaciais), as instituições, as redes multiescalares, as relações sociais e a natureza exterior ao homem; e de que o SIAL é um espaço elaborado, fruto de uma construção social, impregnada de características culturais (Diáz-Bautista, 2001). Nesse sentido, acredita-se que a produção da uva em Marialva pode ser caracterizada como um SIAL, principalmente considerando o desenvolvimento da agricultura familiar e a ênfase no território. Apesar de o município ser um grande produtor de commodity, as características da uva consomem grande quantidade de mão de obra e podem ser desenvolvidas de forma vantajosa em pequenas propriedades, o que assegura boas condições socioeconômicas para a população rural. Vale destacar que o sistema de parcerias vigente também dissemina conhecimento, distribui a renda e garante mão de obra especializada, tornando a uva de Marialva um ativo específico inerente a seu território, como aponta a literatura (Fourcade et al. 2005; Specht \& Ruckert, 2008).

\section{Conclusões}

Retomando a discussão inicial, com o objetivo de compreender as ações e os atores que configuram Marialva como um território produtor de uva fina, avalia-se que vários aspectos convergiram para essa configuração. Portanto, foram investigados de forma interligada aspectos socioeconômicos, políticos, culturais e da natureza que se revelaram por meio do histórico do município. Esses aspectos apontam para a caracterização da produção de uva fina em Marialva como um SIAL, enfatizando a importância do território.

O processo de territorialização da uva fina e a constituição do SIAL em Marialva, a partir da tríade homem-produto-território, envolvem relações de trabalho e ações coletivas para valorização e diferenciação do produto. Tal processo abarca aspectos materiais e simbólicos do território, tais como condições climáticas, conhecimento e afinidade com determinadas técnicas produtivas. Percebe-se que a constituição do SIAL envolveu ações interligadas nas quatro dimensões - economia, política, cultura e natureza - sendo essas determinantes para o desenvolvimento territorial no caso estudado.

A partir da análise desenvolvida, alguns pontos merecem destaque. Primeiramente, analisa-se a premissa acerca dos avanços empíricos de combinar a perspectiva do SIAL com uma abordagem ampliada de território. A princípio, nota-se uma semelhança entre as perspectivas que se embasam na formação de laços históricos, materiais e imateriais com o território. A partir das semelhanças, pode haver um maior aprofundamento para ambas, considerando que cada uma delas privilegia questões diferentes.

Do lado da abordagem do SIAL, acredita-se que a análise E-P-C-N proposta por Saquet (2009) pode revelar questões importantes para a configuração de um território, portanto, pode ser utilizada de forma satisfatória pela abordagem do SIAL. No caso estudado, percebe-se que os aspectos políticos, culturais e da natureza foram tão relevantes quanto o aspecto socioeconômico, demonstrando que essas variáveis estão reciprocamente relacionadas. A abordagem utilizada contemplou o território como resultado de um processo que envolve um conjunto de forças, de relações e produções interconectadas, da articulação mútua dos 
aspectos econômicos, políticos e culturais, e destes com a natureza no tempo e no espaço, coerente com a proposta analítica de Saquet (2009).

Em contrapartida, admite-se que os estudos sobre território que tem como ênfase o desenvolvimento local podem ampliar a discussão, considerando a abordagem de SIAL. Ao incluir os constructos homem e produto ligados ao território, amplia-se o entendimento da territorialização por meio de questóes culturais, econômicas e políticas, auxiliando na compreensão das relações de poder, nas redes e na percepção identitária existentes em determinado território.

Além disso, frisa-se que o desenvolvimento local deve ser alvo de discussão e análise por parte dos agentes públicos e da sociedade civil organizada. Como percebido, no caso estudado, o envolvimento de todos os atores propicia um maior desenvolvimento territorial, sendo que o apoio mais significativo do governo municipal desencadeou ações que disseminaram o território existente. Isso mostra que a articulação de caráter microrregional e intermunicipal tem um papel importante nesse contexto, como afirma Veiga (2005). Para essa discussão, recomenda-se que a perspectiva Slot, apresentada por Dematteis (2005), seja utilizada em estudos futuros, pois pode trazer benefícios e contribuir para o planejamento das potencialidades do território local, para além da discussão do SIAL existente.

Outro ponto a ser examinado é a necessidade de discutir uma melhor articulação para valorização do produto. Como apontado por Almeida e Serra (2012), os principais mercados consumidores já reconhecem a qualidade da uva de Marialva. Portanto, propóe-se a criação de um selo que possa criar uma marca identitária nos clientes, sendo trabalhada sobre a indicação geográfica já obtida para construção dessa marca, construindo uma proximidade simbólica com o consumidor. Essa sugestão vai de encontro com aquelas do desenvolvimento rural, apontado por diversos atores (Veiga, 2005; Specht \& Ruckert, 2008; Moraes \& Schneider, 2010; Boucher \& González, 2011; Lourenzani et al., 2013).

Sendo assim, acredita-se que o estudo contribuiu com uma abordagem ampla, tentando entender os aspectos que contribuíram para a configuração de Marialva como um território produtor de uva fina. Destaca-se a importância de estudos empíricos mais aprofundados, tendo como base as perspectivas teóricas trabalhadas nesta pesquisa. Assim, sugere-se um estudo mais detalhado, envolvendo a coleta de dados primários sobre o SIAL da uva fina em Marialva. Sugere-se ainda, para futuras pesquisas, a análise de configuração de outros territórios, objetivando a formação de conhecimentos mais abrangentes, considerando as questóes econômicas, políticas, culturais e da natureza.

\section{REFERÊNCIAS}

Assembleia Legislativa do Estado do Paraná. (2009). Lei nº 16.231 de 28 de agosto de 2009. Recuperado de http:// portal.alep.pr.gov.br/

Almeida, A.C.S. (2010). A viticultura como base econômica da pequena propriedade no município de Marialva-PR (Dissertação de Mestrado). Universidade Estadual de Maringá, Maringá, PR, Brasil.

Almeida, A.C.S., \& Serra, E. (2012). O papel da colônia japonesa, da EMATER e do governo municipal na implantação e fortalecimento da viticultura no município de Marialva-PR. Campo-Território: Revista de Geografia Agrária, $7(13)$.

Almeida, A.C.S., \& Serra, E. (2013). A viticultura em Marialva-PR - a utilização de mão de obra familiar na cadeia de produção da uva. Geoingá: Revista do Programa de Pós-Graduação em Geografia 5(1).

Alves, A.P., \& Pelegrini, S.C.A. (2010). Histórias e Memórias dos cafeicultores no Paraná: o cotidiano e as práticas de trabalho da população de Marialva (1940-1960). Revista de História Regional, 15(1).

Ambrosini, 1.B., Filippi, E.E., \& Miguel, L.A. (2009). Produção de Queijo Serrano: estratégia de reprodução social dos pecuaristas familiares do sul do Brasil sob a perspectiva multidisciplinar do Sistema Agroalimentar LocalizadoSIAL. Estudo \& Debate, 16(2). 
Agência Sebrae de Notícias Paraná. Produtores de uva de Marialva apostam em novas tecnologias. 07 jul.2015. Disponível em: . Acesso em: 06 jan.2016.

Boucher, F., \& González, J.A.R. (2011). Guia Metodológica para la activación de Sistemas Agroalimentarios Localizados (SIAL). IICA, CIRAD, REDSIAL México-Europa. México: IICA.

Boucher F., Requier-Desjardins, D., \& Brun, V. (2010). SYAL: um nouvel outil pour le developpement de territoires marginaux. Anais do ISDA-Innovation and Sustainable Development in Agriculture and Food. Montpellier, França.

Cândido, P.A., Malafaia, G.C., \& Rezende, M.L. (2012). A exploração do pequi na região norte de Minas Gerais: abordagem por meio do Sistema Agroalimentar Localizado. Revista IDeAS, 5(2).

Confederação da Agricultura e Pecuária do Brasil. Agropecuária supera obstáculos e segue liderando a economia brasileira em 2016. 06 dez. 2016. Recuperado de http://www.cnabrasil.org.br/noticias/agropecuaria-superaobstaculos-e-segue-liderando-economia-brasileira-em-2016

Dematteis, G. (2005). Geografia democrática, território e desenvolvimento local. Formação, 2(12).

Diáz-Bautista, A. (2001). Efectos de la Globalización en la Competitividad y en los Sistemas Productivos Locales de México. Observatorio de la Economía Latinoamericana. Recuperado de http://www.eumed.net/cursecon/ ecolat/mx/index.htm

Ferreira, J.C.V. (2006). Municípios Paranaenses: origens e significados de seus nomes. 21. ed. Curitiba: Secretaria de Estado da Cultura.

Fourcade, C., Muchnik, J., \& Treillon, R. (2005). Système de production localisés: le cas de l'agroalimentaire. GIS SYAL, MAPAAR, DATAR.

Freitas, A. F, Freitas, A. F., \& Dias, M. M. (2012). Gestão social e políticas públicas de desenvolvimento territorial. Administração Pública e Gestão Social, 4(1), 76-100.

Google Street View (2011). Marialva, Paraná. Recuperado de https://www.google.com/maps

Haesbaert, R. (2004). Des-caminhos e perspectivas do território. In: Ribas, A.D., Sposito, E.S., \& Saquet, M.A. Território e desenvolvimento: diferentes abordagens. Francisco Beltrão: UNIOESTE.

Hiera, M.D., \& Silveira, L.M. (2011). A dinâmica climática e as necessidades da videira: estudo de caso Marialva-PR. Geoingá: Revista do Programa de Pós-Graduação em Geografia, 3(2).

Instituto Brasileiro de Geografia e Estatística. (2015).Cidades@. Recuperado de http://cidades.ibge.gov.br/

Instituto Nacional de Proteção Intelectual. INPI. (2017). Pedidos de Indicações Geográficas concedidas e em andamento. Recuperado de http://www.inpi.gov.br/menu-servicos/indicacao-geografica/pedidos-deindicacao-geografica-no-brasil

Sistema IBGE de Recuperação Automática. (2014). Produção Agrícola Municipal 2014. Recuperado de http:// www.sidra.ibge.gov.br/bda/pesquisas/pam/default.asp

Inventário Turístico Marialva-PR. (2015). Sebrae. Marialva.

Instituto Paranaense de Desenvolvimento Econômico e Social. (2002). Modernização da Agricultura Familiar. Curitiba: IPARDES.

Instituto Paranaense de Desenvolvimento Econômico e Social. 02 jan. 2017. Agronegócio e exportações vão impulsionar a economia do Paraná. Recuperado de http://www.ipardes.gov.br/index.php? pg_conteudo=1\&cod_noticia $=816 \mathrm{http}: / /$ www.ipardes.gov.br/index.php?pg_conteudo $=1 \&$ cod_noticia $=816$

Krone, E.E., Thomé da Cruz, F., \& Menasche, R. (2010). Del Lomo de Las mulas a la Clandestinidad: Dilemas entre las Exigencias Legales y el Sistema Tradicional de Producción del Queso Serrano de los Campos de Cima da Serra (Brasil). Anais do EAAE SEMINAR. Parma-Italy: EAAE, 116.

Lins, H.N. (2006). Sistemas agroalimentares localizados: possível "chave de leitura" sobre a maricultura em Santa Catarina. RER, Rio de Janeiro, 44(2).

Lourenzani, A.E.B.S., Bankuti, S.M.S., \& Peterson, H. (2013). Geographical indication and LAFS sustainability: evidences from specialty coofee from the Norte Pioneiro region in Brazil. Anais do Congresso Internacional SIAL. Florianópolis, 6 . 
Malafaia, G.C.; Barcellos, J.O.J. (2006). Sistemas agroalimentares locais e a Visão Baseada em Recursos: construindo vantagens competitivas para a carne bovina gaúcha. Revista de Economia e Agronegócio, 5(1).

Malafaia, G.C., Barcellos, J.O.J., Aguiar, L.K., Azevedo, D.B., \& Pinto, M. (2007). Building competitive advantages to the livestock farming in Rio Grande do Sul: the case of the Indication of Origin to the "Meat of the Gaúcho Pampas". Anais do International Food \& Agribusiness Management Association: 17th Annual World Symposium. Parma-Italy, 17.

Mariani, M. A. P., \& Arruda, D. O. (2010). Território, territorialidade e desenvolvimento local: um estudo de caso dos empreendimentos econômicos solidários de Corumbá/MS. Anais do Congresso da SOBER. Campo Grande/ MS, 48.

Menezes, S.S.M. (2011). Queijo Artesanal: identidade, prática cultural e estratégia de reprodução social em países da América Latina. Revista Geográfica de América Central, n.especial, EGAL, Costa Rica.

Merriam, S. B. (1998). Qualitative research and case study applications in education. San Francisco: Jossey-Bass.

Ministério dos Transportes. (2010). Banco de informações e mapas de transporte-BIT. Recuperado de http:// www2.transportes.gov.br/bit/01-inicial/index.html

Moraes, J.L.A., \& Schneider, S. (2010). Perspectiva territorial e abordagem dos sistemas produtivos localizados rurais: novas referências para o estudo do desenvolvimento rural. Revista Brasileira de Gestão e Desenvolvimento Regional, 6(2).

Muchnik, J., Cañada, J.S., \& Salcido, G.T. (2008). Systèmes agroalimentaires localisés: état des recherches et perspectives. Cahiers Agricultures, 17(6).

Muchnik, J., \& Sautier, D. (1998). Systèmes Agro-alimentaire Localisés et Construction de Territoires. CIRAD.

Muls, L. M. (2008). Desenvolvimento local, espaço e território: o conceito de capital social e a importância da formação de redes entre organismos e instituições locais. Revista EconomiA, Brasília (DF), 9, 1-21, jan/abr.

Prefeitura Municipal de Marialva. (2014). Portal "Parreiral de Uva" será inaugurado durante a Festa da Uva. Recuperado de http://www.marialva.pr.gov.br/comunicacao_2536_0_Portal-\%E2\%80\%9CParreiral-de-Uva $\% \mathrm{E} 2 \% 80 \% 9 \mathrm{D}$-sera-inaugurado-em-breve

Prefeitura Municipal de Marialva. (n.d.). Galeria de fotos. Recuperado de http://www.marialva.pr.gov.br

Projeto Paraná 12 Meses (2017). Curitiba: Simep. Recuperado de http://www.simep.seab.pr.gov.br/pr12meses/ index.html

Raffestin, C. (2009). A produção das estruturas territoriais e sua representação. In: Saquet, M.A., \& Sposito, E.S. (Orgs.), Territórios e territorialidades: teorias, processos e conflitos. São Paulo: Expressão Popular.

Rambo, A.G., \& Filippi, E.E. (2009). Das concepções clássicas à abordagem territorial: para (re)pensar processos de desenvolvimento na agricultura familiar. Revista Brasileira de Gestão e Desenvolvimento Regional, 5(1).

Rambo, A.G., Filippi,, \& Ruckert, A.A. (2007). Cenários contemporâneos de desenvolvimento territorial: aplicabilidade de políticas públicas em contextos locais organizados. Anais do Congresso da SOBER. Londrina: 45.

Requier-Desjardins, D. (1999). Agro-Industria Rural y Sistemas Agroalimentarios Localizados: ¿Cuáles puestas? Quito: PRODAR.

Resolução n. 2191, de 24 de agosto de 1995 (1995). Crédito Rural - Institui o Programa Nacional de Fortalecimento da Agricultura Familiar (PRONAF). Recuperado de http://www.bcb.gov.br/pre/normativos/res/1995/pdf/ res_2191_v3_L.pdf

Roberto, S.R., Assis, A.M., Genta, W., Yamamoto, L.Y., \& Sato, A.J. (2012). 'Black Star”: uma mutação somática natural da uva fina de mesa cv. Brasil. Revista Brasileira de Fruticultura, 34(3).

Roberto, S.R., Yamashita, F., Kanai, H.T., Yano, M.Y., Paiolo, P.A.C., Sasano, E.M., \& Genta, W. (2002). Efeito da época do anelamento de tronco na antecipação da maturação da uva 'Rubi'. Acta Scientiarum, 24(5).

Santos, R.A. (2011). Território e modernização da agricultura no Sudoeste do Paraná. Revista Espaço Acadêmico, 118.

Sato, A.J., \& Roberto, S.R. (2004). A viticultura no Paraná. Universidade Estadual de Londrina. 
Saquet, M.A. (2005). A relação espaço-tempo e a apreensão do movimento em estudos territoriais. Anais do Encontro de Geógrafos da América Latina, São Paulo, 10.

Saquet, M.A. (2009). Por uma abordagem territorial. In: Saquet, M.A., \& Sposito, E.S.(Orgs.), Territórios e territorialidades: teorias, processos e conflitos. São Paulo: Expressão Popular.

Saquet, M.A. (2015). Abordagens e concepções de território. São Paulo: Outras Expressões.

Saquet, M.A., \& Briskievicz, M. (2009). Territorialidade e identidade: um patrimônio no desenvolvimento territorial. Caderno Prudentino de Geografia, 1(31), pp. 3-16.

Schneider, S. (2004). A abordagem territorial do desenvolvimento rural e suas ligações externas. Revista Sociologias, 6(11), Porto Alegre, pp.88-125, jan/jun.

Souza, M.L. (2009). “Território” da divergência (e da confusão): em torno das imprecisas fronteiras de um conceito fundamental. In: Saquet, M.A., Sposito, E.S.(Orgs.), Territórios e territorialidades: teorias, processos e conflitos. São Paulo: Expressão Popular.

Specht, S., \& Ruckert, A.A. (2008). Sistema Agroalimentar local: uma abordagem para a análise da produção de morangos, no vale do Caí, RS. Anais do Congresso da SOBER. Rio Branco, 46.

Specht, S. (2014). Morangos do Vale do Caí-RS: um sistema agroalimentar territorializado. Campo-Território: Revista de Geografia Agrária, 9(19).

Teixeira, T.R.A., Andrade, Á.A.V. (2010). O conceito de território como categoria de análise. Anais do Encontro Nacional dos Geógrafos. Porto Alegre, 16.

Tonin, T.A., Muniz, A.S., Scapim, C.A., Silva, M.A.G., Albrecht, L.P., \& Conrado, T.V. (2009). Avaliação do estado nutricional das cultivares de uva Itália e rubi no município de Marialva, Estado do Paraná. Acta Scientiarum Agronomy, 31(1).

Triviños, A.N.S. (2010). Introdução à pesquisa em ciências sociais: a pesquisa qualitativa em educação. Atlas: São Paulo.

Vale, A.L.F., Saquet, M.A., \& Santos, R. (2005). O território: diferentes abordagens e conceito-chave para a compreensão da migração. Faz Ciência-Sociedade, Espaço e Economia, 7(1).

Veiga, J.E. (2005). A história não os absolverá nem a geografia. Armazén do Ipê (Autores Associados): Campinas-SP.

\section{Notas}

i O PRONAF é um programa de crédito rural instituído pela Resolução no 2191 de 24 de agosto de 1995 por meio do Conselho Monetário Nacional. O programa é "destinado ao apoio financeiro às atividades agropecuárias exploradas mediante emprego direto da força de trabalho do produtor e de sua família” (Resolução n. 2191, 1995).

ii O Paraná 12 Meses é um projeto do Governo do Estado do Paraná, em parceria com o Banco Mundial, que apoia financeiramente diversas atividades como forma de reduzir a situação de pobreza no meio rural e fomentar o manejo e conservação dos recursos naturais. Dos investimentos realizados, 50\% são financiados pelo Banco Mundial (Projeto Paraná 12 Meses, 2017).

\section{BY-NC-ND}

